\title{
Legados da disciplina histórica: experiências na fronteira entre consensos e horizontes
}

\author{
Andre de Lemos Freixo*
}

Malerba, Jurandir (Org.). Liçôes de História: o caminho da ciência no longo século XIX. Rio de Janeiro: FGV Editora; Porto Alegre: EdiPUCRS, 2010. 492p.

(Org.). Liçôes de História: da história científica à crítica da razão metódica no limiar do século XX. Rio de Janeiro: FGV Editora; Porto Alegre: EdiPUCRS, 2013. 539p.

Em Liçôes dos mestres, George Steiner nos apresentou um ensaio sobre relaçôes entre mestres e discípulos, professores e alunos, todos eles "clássicos", por assim dizer: Sócrates e Platão, Jesus e seus apóstolos, Confúcio e os budistas, Virgílio e Dante, Husserl e Heidegger, entre muitos outros. No cerne de sua reflexão está o problema da educação. E ele indaga sobre essa questão a partir do significado da ideia de "transmissão" e de para quem seria legítimo transmitir saberes, bem como sobre as relaçôes (de continuidade e descontinuidade) entre traditio — "aquilo que se transmite" - e o que os gregos chamavam paradidomena - "aquilo que se transmite agora". ${ }^{1}$ Em suma, o que

${ }^{1}$ STEINER, George. Liçôes dos mestres. Rio de Janeiro: Record, 2005, p. 12-13. significa passar adiante o patrimônio cultural acumulado e herdado? E como fazê-lo? Em escala mais restrita, pode-se dizer que a coleção Liçôes de História se coloca na esteira dessas reflexôes, mesmo que não as tematize ou confronte diretamente.

A coleção tem dois volumes e foi organizada por Jurandir Malerba, titular livre de História na Universidade Federal do Rio Grande do Sul. Seguindo o modelo clássico das antologias, o resultado final é uma obra de história intelectual cujo "público-alvo" parece ser o de estudantes de história e jovens professores em busca de material de qualidade a respeito dos autores que, segundo o organizador, "deixaram um legado monumental para o pensamento moderno" (I, p. 7), ${ }^{2}$ em especial para a historiografia.

Deste modo, pode-se pensar em uma questáo de educaçáo e transmissáo aqui também. Ou, pelo menos, de uma "herança" ou perspectivas nesse sentido, enfeixadas num enredo mais ou menos já conhecido: contar uma parte considerada muito importante da história da formação do campo disciplinar da história. Seja como for, ela precisa ser lida

${ }^{2}$ Para economia do texto, citarei apenas "(I, p. x)", em referência ao primeiro volume, e "(II, p. x)" ao segundo da coleção. 
e pensada como uma história possivel da história. Como uma leitura para sua formação disciplinar. O que provavelmente é realizado sob as lentes de quem se considera parte constituinte do processo. Que hoje reconhece nesses pioneiros algo do que fazemos (embora não façamos mais da mesma maneira) quando escrevemos história. Nesse sentido, digo que elas seguem um enredo "já conhecido", ilustrando um relativo consenso.

Evidentemente, toda seleção implica o descarte de outras referências que poderiam igualmente ser consideradas (pelas mesmas razões propostas pela coleção) tão relevantes quanto as elencadas. No entanto, os autores que figuram nos volumes abarcam um recorte longo, que se estende, aproximadamente, entre 1785 até a década de 1930. Assim, cabe ressaltar o mérito em ultrapassar alguns limites do já referido acordo consensual. Isso enriquece nosso quadro náo apenas de autores conhecidos (ou apresentados), mas ajuda a complexificar o entendimento, por vezes simplista, esquemático e teleológico, do processo de configuração do campo disciplinar da História, suas idas e vindas, desafios e dilemas. Traduçóes de textos de Voltaire, Pierre Daunou, Georg G. Gervinus, Thomas B. Macaulay, Louis Bordeau, Ernst Troeltsch, Karl Lamprecht, Wilhelm Windelband, Friedrich Meinecke, Heinrich Rickert, Benedetto Croce, Robin G. Collingwood, Charles Beard, Carl Becker, James Harvey Robinson, entre outros, ampliam o rol de referências e tradiçóes intelectuais disponíveis aos jovens estudiosos brasileiros de História.

Eleito pela Revista Brasileira de História e Ciências Sociais o "Livro do Ano" (2011), o primeiro volume da coleção apresenta, além dos textos dos mestres modernos, introduções às obras desses autores realizadas por quinze profissionais brasileiros de latitudes geográficas bastante distintas. A introdução do volume ficou a cargo de François Dosse. Seu texto é sintético e procura dar tom e diapasão àquele conjunto de referências, que tem por objetivo (re)traçar o caminho da história oitocentista "rumo à ciência". Caminhos bastante diferentes, como observa Malerba (I, p .8), mas que na introdução de Dosse não se evidenciam em toda sua extensão, uma vez que este prioriza as contribuições francesas para esse desenvolvimento. Os esforços para constituir disciplinarmente qualquer saber necessitam de um relativo consenso sobre quais as referências que devem figurar como incontornáveis para o desenvolvimento da "nova" disciplina. Isso não significa desconsiderar as tensões envolvidas no processo. Erudito e competente, embora por vezes excessivamente simplista, o texto de Dosse destoa um pouco da proposta mais alargada que a coleção promete, mantendo-se fiel ao consenso francês. Seu conceito de historicismo, assim, torna-se restrito, referindo-se quase exclusivamente a uma "história ligada ao particular" que teria "nascido" apenas com Wilhelm von Humboldt (I, p. 25) no seu texto "Sobre a tarefa dos historiadores" (1821). ${ }^{3}$ Além disso, como

\footnotetext{
${ }^{3}$ Como nos ensina Estevão Rezende Martins, o termo "historicismo" deriva de uma tradução de "segunda mão": Historicism (no inglês) que verteu Historismus, termo inicialmente empregado por Friedrich Schlegel ainda em fins do século XVIII. Ver: MARTINS, Estevão de Rezende. Historicismo: o útil e o desagradável. In: ARAUJO, Valdei Lopes de... [et al.] (Orgs.). A dinâmica do historicismo: revisitando a
} 
se poderá ver nos textos introdutórios assinados por Julio Bentivoglio, Sérgio da Mata, Sérgio Duarte, Arthur Alfaix Assis, entre outros, a historiografia oitocentista alemã formulou propostas inovadoras e originais, amparada em sólida erudição e profunda sensibilidade epistemológica, cujas preocupaçôes envolviam reflexôes sobre método, crítica documental, ética, valores, o papel e funçáo social dos historiadores, a problemática da escrita histórica, entre outras. $\mathrm{O}$ recurso a comparaçôes entre as historiografias francesa e alemã também figura como fator mais problemático do que propriamente problematizado por Dosse. Com algum exagero, assevera, por exemplo, que a Introduction aux études historiques (1898), de Langlois e Seignobos, seria capaz de concorrer com o Grundriss der Historik (1857-1858) de Johann Gustav Droysen (I, p. 28). ${ }^{4}$ Tratam-

historiografia moderna. Belo Horizonte: Argvmentvm, 2008, p. 15-48. Ou ainda, Sérgio da Mata, na esteira de A. Wehling, analisou que o historicismo pode também ser definido como uma atitude (espiritual) diante da realidade, da vida e da cultura, mas que emergiu entre fins do XVIII e inícios do século XIX. Pode-se dizer que nesta definição consta um pouco da visão de Herder, lamentavelmente ausente na coletânea, além, sem dúvida, das perspectivas de Ernst Troeltsch e Friedrich Meinecke. Ver: MATA, Sérgio da. Elogio do historicismo. In: ARAUJO, Valdei Lopes de... [et al.] (Orgs.). A dinâmica do historicismo: revisitando a historiografia moderna, op. cit., p. 49-62. Esses dois últimos autores (como poderá ser conferido nas suas respectivas sessões da coletânea) definiram para o impulso historicista alemão em direção à realidade, cada um a sua maneira, a dinâmica da mudança no tempo (desenvolvimento) além, é claro, do caráter irrepetível dos fenômenos humanos, como bem salientou Dosse.

${ }^{4}$ No Brasil, a obra de Droysen foi lançada sob o título Manual de teoria da história, com tradução de Sara Baldus e Júlio Bentivoglio. Este último contribuiu para a coleçáo, assinando pelos textos de dois auto- -se de textos de naturezas muito diversas. Inclusive, o compêndio de Droysen (outro autor decisivo, porém não contemplado nesta coleção) sintetiza as reflexóes de natureza teórica e metodológica que pouco se assemelham à definição das etapas da pesquisa à escrita histórica e à deontologia científica dos historiadores proposta no manual dos franceses. 5 Evidentemente, não se trata de criar ou sustentar competiçóes inócuas, mas evidenciar que a historiografia oitocentista e os historicismos foram muito mais ricos e multifacetados do que a já bastante datada dicotomia do "velho" e do "novo" permitem perceber. $\mathrm{Na}$ economia do texto introdutório de Dosse, portanto, o conceito de historicismo termina por funcionar como a preparaçáo ideal para a triunfal emergência da Sociologia (durkheimiana) para colocar ordem na "casa de Clio" (I, p. 30). Não há nada de errado nisso, mas apenas conserva-se o já conhecido e tradicionalíssimo consenso historiográfico francês a este respeito.

Quanto aos textos escolhidos para tradução, o primeiro volume nos apresenta belos testemunhos de épocas passadas. Suas perspectivas e sociedades são reveladoras de

res seminais do pensamento histórico oitocentista, Leopold von Ranke e G. G. Gervinus, ambos no primeiro volume da Coleção. DROYSEN, Johann Gustav. Manual de teoria da história. Petrópolis, RJ: Vozes, 2009.

${ }^{5}$ Sobre Droysen e o monumental projeto de sua Teoria da História (Historik), ver: CALDAS, Pedro S. Que significa pensar historicamente: uma interpretação da teoria da história de Johann Gustav Droysen. Tese (Doutorado) — Departamento de História da PUC-Rio, Rio de Janeiro, 2004. Ver também: ASSIS, Arthur A. What Is History For? Johann Gustav Droysen and the Functions of Historiography. Nova York: Berghahn Books, 2014. 
muitos e distintos aspectos das relaçóes entre tempo e história, passado e presente. Muitos dos autores podem ser caracterizados como filósofos, no sentido pleno da expressão (por sua capacidade de análise conceitual e abstrata), pois refletem sobre história a partir do que julgavam ser o seu caráter, se literatura ou ciência.

Não caberia aqui debater todas essas leituras em filigrana, a maioria delas é composta por traduçóes de textos inéditos em língua portuguesa. Mas são dignas de nota as palavras de Voltaire em suas meditaçóes sobre história, ou melhor, histórias. Isso pode deixar o leitor contemporâneo relativamente surpreso diante dos muitos sentidos que ele definia o conceito de história, já grafado no singular, mas que podia ser "sagrada ou profana", "filosófica” ou "pragmática”, com suas certezas possíveis e algumas incertezas também, de utilidades como a ilustração moral dos homens de Estado pela via da exemplaridade e da comparação entre culturas, e suas finalidades universais, assim como dotada de algumas "desvantagens" - como as histórias "satíricas": que apesar de dever ser sempre verdadeira e nunca omitir-se, não deveria revelar aspectos particulares que afrontam ao bem maior (dos Estados), sendo portanto avessas ao espírito que defendia. $\mathrm{O}$ texto ajuda o leitor brasileiro a elucidar alguns pontos relativamente enigmáticos, por exemplo, da dissertação de Carl F. Ph. Von Martius, sem dúvida leitor de Voltaire, acerca do como deveria ser escrita a História do Brasil (1843). Seus comentários sobre método e estilo na escrita, uma arte rara, diziam ambos, que envolvia beleza, elaboração, eloquência, gravidade, acuidade e erudição, sempre tomando por base mestres antigos como Tito Lívio, Tácito e Políbio. No mesmo espírito universal do filósofo da história Voltaire, Pierre Daunou, catedrático de História e Moral no Collège de France, republicano francês de primeira hora (1789) e opositor ferrenho de Robespierre e do Terror, relacionava o valor da história a sua utilidade de ilustrar os homens. Em sua preleção de posse à cátedra citada (em 1819), a história e a instrução da prudência contemporânea assumem lugar central. "Cabe à história começar o que acaba o hábito dos negócios, lançar nos espíritos atentos os primeiros elementos do conhecimento dos homens e os germes dessa verdadeira sabedoria que se compóe de prudência e de probidade [...]" (I, p. 80).

As inspiradoras palavras de Lord Acton, aos "companheiros estudantes", sobre o poder das ideias de movimento e mudança presentes na perspectiva dos historiadores modernos sobre a chave da "Lei da Estabilidade", que compele os homens "a compartilhar da existência de sociedades mais amplas que as nossas próximas, a sermos familiares com tipos diferentes e exóticos [...]" (I, p. 265). $\mathrm{Ou}$ ainda as instigantes reflexóes de Louis Bordeau sobre a necessidade lógico-existencial do progresso para a vida humana: a "lei de um contínuo crescimento, de um porvir sem final previsto" (I, p. 304-305). Isto é, a necessidade da história de educar, de transmitir e de estimular o desenvolvimento da capacidade de aprimoramento humana no seu processo de civilizar-se, ou seja, de aumentar sua capacidade para o bem-estar de todos. As prudentes observaçóes de Ernst 
Troeltsch sobre a "crise da ciência histórica" (1922) igualmente têm interesse bastante atual. À sua época, e em sua leitura, a crise se inseria entre os muitos rescaldos dos acontecimentos da Guerra Mundial (19141918). Nesse sentido, o "gigantesco alimento" espiritual (cultura histórica) produzido pela ciência histórica vigorosa, organizada, especializada e profissional paulatinamente afugentava interesses mais espontâneos da juventude na qual sua geração depositava as esperanças por um futuro melhor. A ciência histórica tornou-se impessoal demais, rígida demais, curiosamente se aproximando daquilo que as ciências naturais faziam há tempos. A juventude, agora acusada de a-histórica, espantava-se diante do monumento de erudiçáo exigido pela ciência da história. Eis o problema: "A opção pela barbárie, que para muitos hoje nos ronda como espectro ameaçador ou como salvação sedutora, é onde se instala a consequência de amplas transformaçôes mundiais, e não a resoluçáo de uma juventude afogada em livros" (I, p. 451). Em uma palavra, a crise dos fundamentos filosóficos gerais, das concepçóes dos valores históricos e dos elementos constitutivos do pensamento histórico diante dos rumos da humanidade, das necessidades da vida, dos dilemas do presente, que clamam por respostas novas. Fundamentos formulados em tempos "de paz" já não dariam mais conta de embasar uma ciência humana diante das experiências e eventos terríveis como a guerra de trincheiras, por exemplo.

Neste espírito, o segundo volume segue a forma do anterior, igualmente refletindo sobre a natureza da história. Com o texto introdutório a cargo de Allan Megill, tem-se um autor em maior sintonia com o volume que ele apresenta e com o espírito da coleção. A seleção de autores segue a mesma linha analisada anteriormente, porém, prioriza as críticas ao historicismo - ou à "razão metódica" - que emergiram num contexto em que as certezas do progresso e da civilizaçáo do mundo liberal burguês europeu do fin-de-siècle: um "em tempo de crise existencial” (II, p. 11). Megill conduz sua introdução seguindo o fio das formulaçôes da "teoria da história", ou de um "segundo tempo" de teóricos da história que julga decisivo para a reestruturaçáo do lugar e do papel da história como saber científico (moderno) no mundo ocidental.

Primeiramente, cabe destacar que Megill emprega um conceito específico de teoria da história, cuja afinidade maior repousa sobre o grande projeto de Jörn Rüsen, evidentemente ao lado de outros historiadores vinculados ao que se poderia chamar de "Droysen Renaissance". Assim, teoria da história é aqui compreendida como elaboração de uma reflexão do sujeito do conhecimento sobre si mesmo e sua operação enquanto produção de conhecimento cientifico. Assim, a teoria da história acontece como autorreflexão incessante do pensamento histórico: que antecede (torna possível), ultrapassa (é intersubjetivo) e, necessariamente, atravessa de uma ponta a outra o trabalho histórico. ${ }^{6}$ Em uma

\footnotetext{
${ }^{6}$ Para Rüsen, a teoria da história apreende os fatores determinantes do conhecimento histórico, aqueles que delimitam o campo inteiro da pesquisa histórica e da historiografia. Identificá-los todos e demonstrar sua interdependência sistemática é o que seu projeto almeja. Esse sistema é dinâmico e o autor assevera
} 
palavra, para Megill, teoria da história não é mero adereço (ou apêndice) ao trabalho empírico, mas o próprio âmbito reflexivo que constitui e torna exequível e reconhecível a pesquisa e a escrita como sendo históricas a partir da reflexão sobre princípios, conceitos, procedimentos, estratégias e funçóes daquilo que fazem os historiadores quando fazem história buscando, com isso, compreender criticamente tudo o que está envolvido em tal operação.

É neste sentido que Megill enreda os autores selecionados para o segundo volume a partir do conceito de teoria da história. $\mathrm{Ou}$ seja, compreender e distinguir a história de outras ciências ou saberes seria o objetivo ideal que confere coesão a esse grupo. Diante do desafio positivista de formular "a" ciência de uma vez por todas, rejeitando quaisquer outras formas de história como a-científicas, a própria exploração teórica dos projetos historiográficos tornou-se parte do fazer histórico. Nesta análise, a questão fundamental é: "Qual a natureza da disciplina histórica?” (II, p. 19-20). De muitas formas ela é atravessada por antinomias, como a diferenciação entre ciências do espírito (Geisteswissenschaften) das ciências da natureza (Naturwissenschaften). Sob essa luz

que o historiador deve saber articular tais reflexôes a uma "matriz disciplinar", que se caracteriza pelo envolvimento circular de cinco elementos fundamentais: ideias, métodos, formas, funçóes e interesses. Segundo ele, essa matriz é uma formulação conceitual (teórica), mas subjaz à racionalidade que ele diz estar na base de toda instituição de sentido histórico. Ver: RÜSEN, Jörn. Razão histórica I. Teoria da História: os fundamentos da ciência histórica. Tradução de Estevão Rezende Martins. Brasília: Editora UnB, 2001. pode-se entender, por exemplo, a questáo do particular e do geral de W. Windelband (II, p. 152-169), K. Lamprecht (II, p. 137-146) e F. Meinecke (II, p. 263-271); a diferenciação entre ciências nomotéticas e idiográficas, presentes no idealismo neokantiano de $\mathrm{H}$. Rickert (II, p. 185-199) e W. Dilthey (II, p.1 24-129); ou ainda as duas éticas de M. Weber (II, p. 226-230), a "ética de convicção" (vida pessoal) e a "ética de responsabilidade" (vida política). Essas últimas figuram como parte da solução weberiana para o crítico debate sobre qual seria o procedimento mais indicado para a produção de conhecimento sobre as coisas humanas. A aliança entre história e sociologia, ambas compreensivas, na proposta de Weber, em que a primeira estaria irremediavelmente atada aos desenvolvimentos conceituais (formulaçôes oriundas de reflexóes empíricas de um inventário das diferenças) da segunda, para pensar casos individuais de modo comparativo. Há outras alternativas, é claro.

O nome de um filósofo como Nietzsche não poderia, no entanto, ser facilmente integrado a este conjunto. E se autores como Weber, Collingwood ou Croce podem figurar ali, para Megill a presença do Solitário de Sils Maria entre os eminentes historiadores e teóricos resulta em incômodo. Os primeiros teriam conseguido, como "verdadeiros" teóricos da história, "redefinir a objetividade histórica", de modo a preservar "sua utilidade como, no mínimo, uma ideia reguladora" (II, p.35). De modo que, se por um lado ele reconheceu o mérito de Nietzsche ter afirmado que tudo passa, "não há fatos eternos" (II, p. 18), por outro, pesa-o como um críti- 
co assaz feroz da cultura moderna e de seu projeto crítico. Náo posso deixar de notar em sua crítica o peso de seu posicionamento epistêmico (pró-objetividade, rigor e verdade). Isto é, sua artilharia se volta mais às alternativas teóricas inspiradas no pensamento de Nietzsche, como a meta-história de Hayden White, por exemplo, do que ao filólogo propriamente. Porém, não deixa de estigmatizar como o "santo padroeiro do ataque contra as noçóes impregnadas de progresso" (II, p. 26) como uma personalidade que "os historiadores poderiam facilmente desprezar - afinal de contas, era um extremista, um louco e um filósofo" (II, p. 27).

Ora, apesar de a coleção ser "de história, sobre historiadores e feito por historiadores", como esclarece o organizador (I, p. 7), há também espaço para a sempre bem-vinda interdisciplinaridade. Isso prevalece no primeiro volume, com as contribuiçóes da antropóloga Lilia Moritz Schwartz, do filósofo e educador Leandro Konder (1936-2014), da socióloga e cientista política Teresa Cristina Kirschner e da tradutora, mestre e doutora em Letras Daniela Kern. Evidentemente, os historiadores de ofício (Teresa Malatian, Julio Bentivoglio, Sérgio Campos Gonçalves, Marco Antonio Lopes, Temístocles Cezar, Helenice Rodrigues da Silva, Raimundo Barroso Cordeiro Júnior, José Carlos Reis e Sérgio da Mata, além, é claro, de Dosse e do próprio organizador da antologia) prevalecem em número e, sem dúvida, parte decisiva da atividade profissional deles envolve pesquisas sérias em história intelectual, das ideias e/ou da historiografia. O segundo volume é praticamente todo composto por contribuiçóes introdutórias de historiadores profissionais (Cássio Fernandes, Oswaldo Giacoia Jr., José Carlos Reis, Sérgio Duarte, Carlos Oiti Berbert Jr., Sérgio da Mata, René Gertz, Pedro Caldas, Arthur A. Assis, Núncia Santoro de Constantino, Cristiano Arrais, Sérgio Campos Gonçalves, Edgar e Mauro de Decca, Carlos Aguirre Rojas, Raimundo Barroso Cordeiro Jr., além de Allan Megill e Jurandir Malerba). Talvez o recorte disciplinar privilegiado no segundo volume tenha por meta evidenciar a importância e a necessidade do campo histórico como sendo parte de um conjunto de reflexóes racionais, mais e mais especializadas, de um projeto crítico do qual o "segundo tempo de teóricos da história" faz parte e ainda poderia ensinar muito, no qual a história se tornou o que de melhor poderia se esperar: uma ciência como, ao final do volume poderá ser identificada nas palavras de Lucien Febvre (II, p. 488). Ou ainda, como sustenta Megill, que as tarefas do historiador consistiriam somente em conduzir pesquisas históricas, ensinar história e produzir relatos da história - levando em conta os dilemas e desafios da contemporaneidade. Aliás, a questão da contemporaneidade da história pode ser analisada de modo excepcional nas obras daqueles que versaram sobre a relação da história com o presente, como Benedetto Croce, Robin George Collingwood, ou ainda de autores como Charles Beard, James Harvey Robinson e Marc Bloch e Lucien Febvre.

Seria injusto destacar méritos individuais aqui, uma vez que todos os ensaios introdutórios cumprem com sua função de relacionar aspectos importantes da vida e obra 
do autor apresentado ao texto inédito deste que se segue, tendo os artigos sido realizados por um grupo de profissionais de reconhecida experiência e competência. Alguns desses textos são mais concisos. Outros, contudo, ultrapassam bastante as expectativas, sendo tâo analíticos e pormenorizados que, por vezes, ultrapassam os limites dos textos que deveriam apresentar. É o caso, por exemplo, da introdução de "Fado e história", 7 de Nietzsche, de Oswaldo Giacoia Junior. Seu texto aprofunda passo a passo as meditaçôes sobre a utilidade e desvantagens da história (Historie) para a Vida, escrita por Nietzsche quase vinte anos depois de "Fado e história" (1874), assim como seus desenvolvimentos em sua Genealogia da moral e Para além do bem e do mal. Mais do que isso, apresenta claramente ser um leitor de Nietzsche na esteira de Martin Heidegger, para o qual o historicismo, como perspectiva de consideração da história, perderia de vista o essencial:

[...] que o sentido histórico, é antes de tudo, o vetor que se abre no sentido da historicidade da condição humana, cuja natureza essencial se determina em relação ao tempo, à passagem do tempo, nas dimensóes do passado, do presente e do futuro, e, portanto, em relação às experiências fundamentais do ser humano com a finitude, o sofrimento e a morte, cujo

\footnotetext{
${ }^{7}$ A tradução do alemão aqui é inédita, embora este texto não seja inteiramente desconhecido do público brasileiro. Foi traduzido, a partir da versão espanhola, como "Fatum e história". In: NIETZSCHE, Friedrich Wilhelm. Escritos sobre história. Tradução de Noéli Correia de Melo Sobrinho. Rio de Janeiro: Ed. PUC-Rio; São Paulo: Loyola, 2005, p. 59-65.
}

sentido somente se descerra no horizonte existencial do tempo. (II, p. 93)

Assim, ao terminar a leitura, não posso deixar de lamentar que a coleção se encerre apenas nestes dois volumes. Retomando um pouco a referência ao texto de George Steiner, com a qual escolhi abrir esta resenha, e a diferença entre traditio e paradidomena, é de se lamentar que tenha ficado de fora do projeto todo o debate contemporâneo (de 1945 até os dias de hoje), com autores importantes e questôes decisivas da historiografia que, ainda hoje, suscitam debates. Isto renderia alguns volumes interessantíssimos e enormemente enriquecedores nos quais poderiam ser abordadas as reflexôes sobre duração (Braudel); a importante História dos Conceitos (Begriffsgeschichte) e as reflexōes sobre o tempo histórico (Reinhart Koselleck); a micro-história italiana (Carlo Ginzburg e Giovanni Levi); a problemática da operação historiográfica na sociologia do conhecimento histórico de Michel de Certeau; as contribuições da epistemologia histórica de Michel Foucault, que reconstrói estruturas de regimes discursivos e propóe uma arqueologia do saber (por períodos epistêmicos) na fronteira entre linguagem, economia e vida; o projeto teórico de Jörn Rüsen; as relaçóes entre história e psicanálise (Jan Assmann e Peter Gay); entre história e trauma (Dominick LaCapra, Saul Friedlander); a retomada do debate sobre as relaçóes entre história e literatura (Stephen Greenblatt); o debate sobre ética e poética em historiografia desde o Metahistory de Hayden White (seguido por autores tão diferentes quanto Kei- 
th Jenkins, Frank Ankersmit, Herman Paul e outros); as questóes e problemas suscitados pelo linguistic turn; a viragem para o tratamento da historicidade na fenomenologia ontológica de Martin Heidegger; a filosofia hermenêutica de Hans-Georg Gadamer; as reflexôes de Paul Ricoeur sobre as problemáticas relaçóes entre memória, história e esquecimento (e perdáo); a defesa do niilismo (ativo) de Gianni Vattimo; as recentes e promissoras reflexôes entre história e filosofia da presença (Hans Ulrich Gumbrecht e Ethan Kleinberg); o giro ético-político, o deslocamento do pensamento de matriz metafísica pela ética e pelo engajamento no mundo (Jacques Derrida); entre tantos outros autores/ temas. Tais obras fariam uma enorme diferença no panorama apresentado, pois daria sequência a importantes diálogos presentes nos dois volumes que constituem a coleção.

Inclusive, o aumento exponencial de referências e debates auxiliaria a desfazer o panorama em que o formato "histórico-sociológico-científico" da história (o projeto crítico moderno) - profundamente enraizado no paradigma historicista —, apesar de toda sua autocrítica, autorreflexão e erudição, parece ainda constituir o "sentido" (ou o "fim") de um desenvolvimento linear e progressivo da disciplina. Avanço retilíneo no qual o tempo dos historiadores (configurado em suas narrativas) se confunde com o tempo "em si" e com a própria história. Ora, está em questão aqui um desejo por transmissão; uma herança captada que se quer patrimônio. Portanto, que reflete algo para o presente. Se este é um dos caminhos possíveis, é desejável supor que outras dire- çôes possam se desenhar nos horizontes dos historiadores se e quando o esforço de investigação dos autores e tradiçóes intelectuais, filosóficas e historiográficas for impulsionado por uma força analítica que retire seu vigor de algo além da curiosidade (genealógica), ou da propriedade, de uma "história da história” disciplinar. Exercício que, embora crítico e quase sempre muitíssimo bem feito, muitas vezes termina por restringir nossas perspectivas teóricas e historiográficas no (e ao) presente, em vez de alargá-las. A história da historiografia, hoje talvez mais do que a história intelectual e a das ideias, pode oferecer meios para abrir ainda mais o nosso campo de possibilidades.

Finalmente, a publicaçáo da coleção evidencia o crescimento e o fortalecimento qualitativo do campo de Teoria da História e História da Historiografia nos últimos anos no Brasil. Pode-se perceber isso entre os professores convidados para ambos os volumes, muitos deles figuras de atuação e destaque no campo. Reflete-se aqui o aumento do espaço que as revistas especializadas dedicaram a esse enfoque, ${ }^{8}$ elevando o rigor analítico e de pesquisa. Isso também é mensurável nas propostas de simpósios temáticos e minicursos oferecidos nos disputadíssimos encontros nacionais e regionais da ANPUH, além de outros eventos, tanto os de caráter local quanto nacional, que se consolidam como parte permanente da agenda dos especialistas desta

${ }^{8}$ O Brasil hoje conta com a História da Historiografia, revista Qualis A1 (de excelência, segundo a Capes) exclusivamente dedicada aos grandes temas e subtemas da Teoria da História e da História da Historiografia. 
comunidade. ' Todo professor de história que trabalhe com história da historiografia, história intelectual, história das ideias e teoria da história, ciente de que não se tratam da mesma coisa, sabe das dificuldades de encontrar bom material sobre alguns desses "mestres" e debates do (e no) passado. Temos aqui uma contribuição valiosa à bibliografia sobre história e historiadores modernos. A coleção, sem dúvida, ajuda a dirimir algumas das muitas lacunas nesse sentido, especialmente em língua portuguesa.

\section{Referências bibliográficas}

ASSIS, Arthur A. What Is History For? Johann Gustav Droysen and the Functions of Historiography. Nova York: Berghahn Books, 2014.

CALDAS, Pedro S. Que significa pensar historicamente: uma interpretação da teoria da história de Johann Gustav Droysen. Tese (Doutorado) - Departamento de Históriada PUC-Rio, Rio de Janeiro, 2004.

DROYSEN, Johann Gustav. Manual de teoria da história. Petrópolis, RJ: Vozes, 2009.

MARTINS, Estevão de Rezende. Historicismo: o útil e o desagradável. In:

\footnotetext{
${ }^{9}$ Entre outros, pode-se destacar também o Simpósio Brasileiro de História da Historiografia (SNHH), realizado anualmente na cidade de Mariana (MG) desde 2006 pelo Núcleo de Estudos de História da Historiografia e Modernidade baseado no Instituto de Ciências Humanas e Sociais da Universidade Federal de Ouro Preto (NEHM/ICHS/UFOP), e berço fundador da Sociedade Brasileira de Teoria e História da Historiografia (SBTHH), em 2009.
}

ARAUJO, Valdei Lopes de... [et al.] (Orgs.). $A$ dinâmica do historicismo: revisitando a historiografia moderna. Belo Horizonte: Argvmentvm, 2008.

MATA, Sérgio da. Elogio do historicismo. In: ARAUJO, Valdei Lopes de... [et al.] (Orgs.). A dinâmica do historicismo: revisitando a historiografia moderna. Belo Horizonte: Argvmentvm, 2008.

NIETZSCHE, Friedrich Wilhelm. Escritos sobre história. Tradução de Noéli Correia de Melo Sobrinho. Rio de Janeiro: Ed. PUCRio; São Paulo: Loyola, 2005, p. 59-65.

RÜSEN, Jörn. Razão histórica I. Teoria da História: os fundamentos da ciência histórica. Tradução de Estevão Rezende Martins. Brasília: Editora UnB, 2001.

STEINER, George. Liçōes dos mestres. Rio de Janeiro: Record, 2005. 